\title{
Conhecimentos Estratégicos Para a Participação Social no Sistema Único de Saúde ${ }^{\#}$ Strategic Knowledge for Social Participation in Unified Health System
}

\author{
Renata Lopes De Siqueira* \\ Rosângela Minardi Mitre Cotta** \\ Jeferson Boechat Soares**
}

\begin{abstract}
Resumo
A participação social no Sistema Único da Saúde (SUS) requer competências técnicas essenciais. O objetivo deste artigo foi avaliar o domínio de informações dos membros do Conselho Municipal de Saúde de Viçosa, Minas Gerais. Por meio de triangulação de métodos que incluiu observação participante, entrevista semiestruturada e análise documental, investigou-se o conhecimento dos conselheiros sobre documentos jurídicos e técnico-administrativos relativos à regulamentação e gestão do SUS. Foram também levantados o número de mandatos, a assiduidade nas reuniões e a participação em oficinas de capacitação. Os dados revelaram iniquidade no domínio de informações em razão do caráter burocrático atribuído aos instrumentos normativos, seu formato técnico e codificado; ausência de apoio técnico. Observou-se também a ocorrência de uma cultura política na qual oscila a defesa de interesses particulares, o autoritarismo, a omissão e/ou desinteresse em relação às causas coletivas. Conclui-se pela necessidade de educação permanente dos conselheiros com vistas à consolidação da participação social. Ignorar a premência desta formação contínua possibilita aos detentores do poder político a perpetuação de práticas autoritárias e incompatíveis com as reais demandas em saúde da população. Entretanto, a superação de tais práticas demanda a adoção de um modelo pedagógico crítico e reflexivo no qual, além do repasse de informações essenciais sobre os conteúdos normativos que os conselheiros precisam dominar para o exercício de suas atribuições, haja a promoção de uma cultura de participação política democrática e de resistência ao autoritarismo e clientelismo comum no sistema política brasileiro, especialmente, nos municípios de pequeno e médio porte.
\end{abstract}

Palavras-chave: Participação social. Conselhos de Saúde. Políticas de Saúde.

\begin{abstract}
Social participation in the Unified Health System (UHS) requires essential technical skills. This paper aims to evaluate the grasp of information by the members of Municipal Health Council of Viçosa, Minas Gerais. By the means of triangulation of the methods, which include participative observation, semi structured interview and documental analysis, it was assessed the knowledge of the counselors on juridical and technical-administrative documents, relative to the regulation and management of UHS. Additionally, we proceeded to survey the number of mandates, attendance at meetings and participation in workshops for Training of Health Counselors. The collected data reveals iniquity in the grasp of information, whose causes refer to: the bureaucratic character attributed to the normative instruments, the highly technical encoded format; the absence of technical support; the poor infrastructure and incipient knowledge of virtual technologies to access information. Also, it was noticed the occurrence of a political culture, in which there is fluctuations of: authoritarianism; defense of private interests in political settings; omission and/or indifference in relation to collective causes. It concludes the need for continuing education of counselors with a view to consolidating the social participation. To neglect the urgency of continuing education enables holders of political power perpetuate their authoritarian practices, which are incompatible with the real demands on public health. However, the overcoming of such practices requires adopting a critical and reflective teaching model, in which, besides the transfer of key information about the normative content that counselors need to master for the exercise of their duties, there is the promotion of a culture of democratic political participation; and resistance to authoritarianism and clientelism, as both of the latter are common in the Brazilian political system, especially in small and medium-sized municipalities.
\end{abstract}

Keywords: Social participation. Health Councils. Health Policies.

\footnotetext{
DOI: $10.15343 / 0104-7809.201539013242$

\# O presente trabalho foi realizado com o apoio da CAPES - Coordenação de Aperfeiçoamento de Pessoal de Nível Superior, entidade do Governo Brasileiro voltada para a formação de Recursos Humanos - AUX-PE-PRO-ENSINO-SAÚDE 2034/2010 - Processo No. 23038.009788/2010-78

\# Artigo resultante da tese de doutorado: Siqueira, Renata Lopes. Análise do perfil técnico, representativo e do potencial das estratégias inovadoras de ensino e aprendizagem no desenvolvimento de competências para a participação social no contexto do Sistema Único de Saúde.2014. Tese apresentada à Universidade Federal de Viçosa, como parte das exigências do Programa de Pós-Graduação em Ciência da Nutrição, para obtenção do título de Doctor Scientiae, Viçosa, Minas Gerais.

* Universidade Federal de Viçosa, Campus UFV, Viçosa, Minas Gerais, Brasil. Email: renata.educacao@gmail.com

** Universidade Federal de Viçosa, Viçosa, Minas Gerais, Brasil.

Os autores declaram não haver conflitos de interesse.
} 


\section{INTRODUÇÃO}

Em maio de 2014, o governo federal, por meio do Decreto No 8.243/14, instituiu a Política Nacional de Participação Social (PNPS) com o intuito de fortalecer a participação e o controle social, tal fato torna imperativa uma reflexão acerca dos desafios a serem superados para a sua efetivação.

No âmbito do Sistema Único de Saúde (SUS), cumprindo a diretriz constitucional de participação social no SUS, a Lei n. ${ }^{\circ} 8.142$, desde 1990, estabeleceu a obrigatoriedade de constituição de Conselhos de Saúde (CS) de caráter permanente e deliberativo que juntamente com as conferências passaram compor as instâncias formais de participação social no SUS ${ }^{1,2}$.

Na prática, o caráter deliberativo dos CS(s) demanda uma dinâmica de interação, na qual os diferentes segmentos, em condições de igualdade de poder, por meio da argumentação, do debate "cara a cara", possam pactuar deliberações acerca das políticas de saúde em prol dos interesses comuns ${ }^{3,4}$.

Estas deliberações estão associadas ao papel legalmente instituído de estudar e decidir sobre as ações e serviços de saúde prestados; fiscalizar quanto e como o governo gasta os recursos financeiros da saúde, além de formular propostas em relação a política de saúde local ${ }^{1,4,5}$.

Não obstante, segundo Bobbio ${ }^{6}$, é necessário considerar que o processo de democratização das sociedades ocorreu em um contexto de Estado progressivamente mais complexo, que apresenta um número cada vez maior de problemas políticos complicados e que requerem competências técnicas também maiores e mais sofisticadas para o homem comum.

Destarte, a consolidação de um sistema de saúde universal que deve ser gerido de forma descentralizada e hierarquizada, e que também deve assegurar atenção integral, em um país de dimensões continentais e com muitas disparidades regionais, esta condicionada a uma série de medidas complexas que representam grande desafio aos gestores, profissionais de saúde e à população ${ }^{7}$.
Consequentemente, implementar a participação social nos moldes idealizados para o SUS requer amplo conhecimento de seus princípios e diretrizes basilares, dos instrumentos normativos, dos mecanismos de gestão, financiamento e operacionalização, assim como, das instâncias e dos procedimentos de controle social. Igualmente, demanda que os conselheiros tenham conhecimento das peculiaridades da realidade em que atuam, de forma a identificar as aspirações e necessidades comunitárias, bem como, os meios e recursos para satisfazê-las $8,7,9,10,11$.

Considerando esta perspectiva, o objetivo do presente trabalho foi avaliar a apropriação (ou não) pelos conselheiros municipais de saúde das informações necessárias à formação de competências técnicas importantes para o cumprimento de suas atribuições.

Ressalva-se que o foco na dimensão técnica constitui um recorte metodológico que não implica desconsideração das dimensões políticas, estruturais e culturais que igualmente interferem na sua atuação dos conselheiros, tais como: falta de infraestrutura e recursos, ausência de uma cultura de participação política, má vontade política em relação ao exercício da cidadania, dentre outros ${ }^{7}$.

Espera-se, a partir do contexto investigado, contribuir para o debate sobre a participação social no SUS, sem, contudo, intencionar o estabelecimento de generalizações homogeneizadoras de caráter a-histórico.

\section{METODOLOGIA}

Trata-se de um estudo qualitativo realizado por meio da triangulação de métodos ${ }^{12}$. Os sujeitos da pesquisa foram os membros do ConseIho Municipal de Saúde de Viçosa (CMS/Viçosa), Minas Gerais.

Investigou-se o conhecimento acerca de documentos técnico-administrativos e normativos relativos à gestão e regulamentação do SUS, utilizando-se como técnica de coleta de dados roteiro de entrevista semiestruturado contendo questões de natureza subjetivas e objetivas.

Adotou-se como parâmetro de análise do domínio técnico-administrativo o conhecimento acerca do Plano de Saúde (PS) municipal e do 
Relatório Anual de Gestão (RAG) e no aspecto jurídico, o conhecimento sobre as Leis Orgânicas da Saúde (LOS) - Leis 8.080/90 e 8.142/90.

Concomitantemente, realizou-se a observação participante e a análise do conteúdo das atas das reuniões ordinárias e extraordinárias do CMS/Viçosa, procedimentos que possibilitaram maior interatividade com o contexto de estudo e a percepção da proximidade entre o discurso e a prática cotidiana do conselho.

Complementarmente, foram investigados o número de mandatos, a frequência nas reuniões do conselho e a participação em oficinas de Capacitação de Conselheiros de Saúde.

Por meio de estatística descritiva levantou-se os indicadores de frequência dos parâmetros técnico-administrativos e jurídicos, adotando-se como ferramenta o software Epi Info, versão 3.5.2.. O conteúdo das atas foi analisado por meio de análise temática conforme técnica preconizada por Bardin ${ }^{13}$.

Foram entrevistados 51 conselheiros do total de 56, sendo que as entrevistas ocorreram no período de abril a junho de 2012. Os motivos da não participação dos demais conselheiros foram: 2 conselheiros não atenderam as inúmeras tentativas de contatos para agendamento da entrevista e; 3 conselheiros alegaram terem solicitado desligamento formal do Conselho no período de estudo.

Entre os conselheiros entrevistados 24 eram suplentes e 27 titulares. Quanto à distribuição por segmento, 4 eram do governo, 10 dos prestadores de serviço, 12 dos trabalhadores da saúde e 26 eram representantes dos usuários. Quanto ao grau de escolaridade, $17,6 \%$ cursaram o ensino fundamental, $19,6 \%$ o ensino médio, e $62,8 \%$ possuíam diploma de curso superior.

Em função da dimensão política do fenômeno da participação social nos conselhos gestores de políticas públicas, adotou-se um referencial teórico de caráter interdisciplinar, que conjugou a perspectiva teórica oriunda da Saúde Coletiva à teoria social sobre democracia, proveniente do campo das Ciências Sociais.

Em cumprimento à Resolução n. ${ }^{\circ}$ 466/12 do Conselho Nacional de Saúde, esta pesquisa foi aprovada pelo Comitê de Ética e Pesquisa com Seres Humanos da UFV, protocolo n. ${ }^{\circ}$ 056/2012. Procedeu-se a divulgação e esclarecimento prévio dos objetivos da pesquisa em reunião ordinária do CMS/Viçosa. Todos os participantes do estudo assinaram o Termo de Consentimento Livre e Esclarecido.

\section{RESULTADOS E DISCUSSÃO}

A CF de 1988 ao reconhecer a saúde como direito universal, desencadeou a necessidade de instituição de novo arcabouço jurídico que regulasse o cumprimento deste direito. Destarte, após CF promulgaram-se as Leis Orgânicas da Saúde (LOS) - 8.080/90 e 8.142/90 - que regulamentam o SUS e, a partir destas, foram estabelecidas uma série de decretos, portarias e resoluções ${ }^{8}$.

As LOS dispõem sobre a forma de organização, funcionamento, financiamento e participação da comunidade na gestão do SUS $4,9,14,15$.

Entre os conselheiros entrevistados, 76,5\% afirmaram terem ouvido falar sobre o conteúdo da Lei n. ${ }^{\circ} 8.080 / 90{ }^{15}$ e $51 \%$ a respeito da Lei $n .{ }^{\circ}$ $8.142^{12}$ (Tabela 1).

Entretanto, apesar de 37,3\% dos conselheiros estarem exercendo seu mandato pela segunda $(6 \%)$, terceira $(9,8 \%)$, quarta $(5,9 \%)$ quinta $(3,9 \%)$ e até sexta vez consecutiva $(3,9 \%)$, a maioria dos conselheiros afirmou desconhecer o conteúdo das LOS (Tabela 1).

A inclusão da saúde entre os direitos sociais fundamentais na CF de 1988 tornou perene o dever do Estado com relação a seu cumprimento por meio de políticas e programas que realizem sua provisão, proteção e promoção. Não obstante, a universalização jurídica ser condição essencial, um direito só o é de fato, se também for reconhecido e usufruído na práxis de seus portadores $^{5}$, no caso desta pesquisa, os usuários do SUS representados pelos conselheiros de saúde.

São as LOS(s) que estabelecem as regras para que o direito à saúde se cumpra, definindo em conjunto, como o SUS deve existir e funcionar, e quais os procedimentos e mecanismos de controle e exigibilidade deste direito ${ }^{7,8}$. 
Tabela 1. Domínio de conhecimento sobre as Leis Orgânicas da Saúde (LOS) pelos Conselheiros de Saúde do município de Viçosa, Minas Gerais, 2013.

\begin{tabular}{|c|c|c|c|c|c|}
\hline \multirow{2}{*}{ Informações sobre as LOS } & \multicolumn{2}{|c|}{ Distribuição } & \multirow{2}{*}{ Informações sobre as LOS } & \multicolumn{2}{|c|}{ Distribuição } \\
\hline & FA & FR $(\%)$ & & FA & FR(\%) \\
\hline \multicolumn{3}{|c|}{ Ouviu falar sobre da Lei no. 8.080/90? } & \multicolumn{3}{|c|}{ Ouviu falar sobre a Lei no. 8.142/90? } \\
\hline Sim & 39 & 76,5 & Sim & 25 & 49,0 \\
\hline Não & 12 & 23,5 & Não & 26 & 51,0 \\
\hline Total & 51 & 100,0 & Total & 51 & 100,0 \\
\hline \multicolumn{3}{|c|}{ Conhece o conteúdo da Lei no. 8.080/90? } & \multicolumn{3}{|c|}{ Conhece o conteúdo da Lei no. 8.142/90? } \\
\hline Sim & 15 & 29,4 & Sim & 12 & 23,5 \\
\hline Não & 36 & 70,6 & Não & 39 & 76,5 \\
\hline Total & 51 & 100,0 & Total & 51 & 100,0 \\
\hline \multicolumn{3}{|l|}{ Leu a Lei no. 8.080/90? } & \multicolumn{3}{|l|}{ Leu a Lei no. 8.142/90? } \\
\hline Sim & 21 & 41,2 & Sim & 17 & 33,3 \\
\hline Não & 30 & 58,8 & Não & 34 & 66,7 \\
\hline Total & 51 & 100,0 & Total & 51 & 100,0 \\
\hline \multicolumn{3}{|c|}{ Quanto leu da Lei no. 8.080/90? } & \multicolumn{3}{|c|}{ Quanto leu da Lei no. 8.142/90? } \\
\hline Integra & 11 & 52,4 & Integra & 8 & 53,3 \\
\hline Partes & 10 & 47,6 & Partes & 7 & 46,7 \\
\hline Total & 21 & 100,0 & Total & 15 & 100,0 \\
\hline \multicolumn{3}{|c|}{ Por qual motivo leu a Lei no. 8.080/90? } & \multicolumn{3}{|c|}{ Por qual motivo leu a Lei no. $8.142 / 90 ?$} \\
\hline Atuação CMS & 4 & 19,0 & Atuação CMS & 5 & 29,4 \\
\hline Concurso público & 6 & 28,6 & Concurso público & 5 & 29,4 \\
\hline Interesse acadêmico & 4 & 19,0 & Interesse acadêmico & 3 & 17,6 \\
\hline Interesse profissional & 5 & 23,8 & Interesse profissional & 2 & 11,8 \\
\hline Outros & 2 & 9,5 & Outros & 2 & 11,8 \\
\hline Total & 21 & 100,0 & Total & 17 & 100,0 \\
\hline
\end{tabular}

Fonte: próprios autores.

É inquietante o fato de a maioria dos conseIheiros de saúde desconhecer o conteúdo da Lei n. ${ }^{\circ} 8.080 / 90$, visto que, a mesma regula as ações e serviços de saúde, sua organização, direção e gestão, inclusive, delimitando as competências e responsabilidades de cada esfera do governo, definindo como deve ser a participação do setor privado, a política de recursos humanos, o financiamento do setor e a participação popular no SUS8 ${ }^{1,4,10,15,16}$. A Lei n. ${ }^{\circ}$ 8.080/90 foi criada, justamente, com o intuito de dar materialidade ao $\mathrm{SUS}^{7,14}$.
A Lei n. ${ }^{\circ} 8.142 / 90$, por sua vez, dispõe de forma mais específica sobre o financiamento e participação social estabelecendo as instâncias, composição e atribuições dos Conselhos e Conferências de Saúde. Esta lei é decorrente de alguns vetos às propostas da Lei n. ${ }^{\circ}$ 8.080/90 que foram percebidos como indevidos por desconsiderarem a necessidade de regulamentação da participação da comunidade e as condições e critérios de transferência dos recursos financeiros a estados e municípios por meio dos Fundos de Saúde $2,7,17$. 
Destarte, pode-se afirmar que a ignorância sobre as LOS pode acarretar diversas consequências negativas entre as quais se destacam três:

Primeira: compromete o controle social, já que não é possível deliberar de forma consciente sobre as ações e serviços de saúde detendo pouca informação sobre os aspectos normativos do sistema sanitário ${ }^{10}$.

Segunda: a falta de conhecimento sobre os instrumentos regulatórios do SUS também compromete a consolidação da saúde como direito, pois nelas estão contidos os efetivos procedimentos e mecanismos de recuperação, proteção, promoção e exigibilidade deste direito.

Terceira: se considerado a perspectiva de teórica do economista indiano Amartya Kumar Sen, na qual a saúde e a educação, de entre outros direitos sociais, são liberdades constitutivas do próprio desenvolvimento social e encontram-se, mútua e complementarmente, condicionadas as liberdades políticas e econômicas, que estimulam os indivíduos a superar racionalmente as privações, levando ao desenvolvimento social ${ }^{18}$, constatar-se-á que o desconhecimento da saúde como direito e dos instrumentos que regulam a sua provisão, pode colocar em risco o próprio desenvolvimento social.

Não obstante, se a informação sobre a legislação é condição essencial para a participação efetiva, o acesso e domínio da mesma por si só não garantem atitude que privilegie as causas sociais.

No contexto deste estudo, dentre os 21 conselheiros que haviam lido - integral ou parcialmente - a Lei n. ${ }^{\circ}$ 8.080/90, quando indagados sobre os motivos que os levaram a leitura, predominou como razão a prestação de exame de concurso público (28,6\%). O intuito de aprimorar sua atuação conselhista para atender aos interesses coletivos revelou-se como motivo secundário, com proporção equivalente à leitura por interesse acadêmico 19,0\% (Tabela 1).

Quanto a Lei n. ${ }^{\circ} 8.142 / 90,33 \%$ dos conselheiros que já haviam a lido e, dentre estes, 53,3\% afirmaram terem lido seu conteúdo na íntegra. Entre os motivos, predominaram as justificativas em prol da prestação de exames de concurso público e para subsidiar a atuação no CMS, ambas justificavas com frequência relativa de 29,4\% (Tabela 1).

Esta preponderância de motivos particulares em detrimento dos coletivos corrobora a perspectiva de que o conhecimento legal não pode ser interpretado como dispositivo mecânico de cidadania. Esta ultima está condicionada pela cultura de participação democrática, na qual os valores e prioridades vigentes determinam o uso que os sujeitos farão das oportunidades de acesso a informação, a articulação e participação ${ }^{18}$.

Esta perspectiva também vai ao encontro da análise de Bobbio $^{6}$ que destaca a necessidade de se reconhecer o contraste entre os ideais democráticos e a "democracia real", observando-se que nesta última, existe uma série de "promessas não cumpridas", entre elas a crença de que a educação para a democracia surgiria do próprio exercício democrático.

Além do marco regulatório é essencial o domínio sobre os instrumentos de gestão do sistema. Desde a criação do SUS muitos foram os esforços e realizações visando promover sua implantação e funcionamento de forma planificada.

Destarte, uma ampla teia de instrumentos de gestão foi desenvolvida com o intuito não somente de embasar e orientar a atuação dos gestores de saúde, mas também de propiciar processos de fiscalização, auditória e controle das ações e serviços prestados, observando-se que os mesmos estão em conformidade com os princípios e diretrizes do SUS definidos na CF de 1988.

O Plano de Saúde (PS) é um instrumento de gestão que apresenta as ações de saúde que deverão ser desenvolvidas pelo município durante determinado período ${ }^{19}$. Sua elaboração está regulada por instrumentos legais, e desde 2006 os PS(s) passaram a ter o compromisso de estar em consonância com a Portaria GM/MS n. ${ }^{\circ} 399$, de 22 de fevereiro de 2006, que regulamento o Pacto pela Saúde.

O PS é um instrumento que, a partir de um diagnóstico situacional, deve refletir as necessidades de saúde da população e apresentar as intenções e os resultados a serem buscados no 
período de quatro anos, expressos em objetivos, diretrizes e metas, servindo de referencia para a gestão e execução do SUS ${ }^{19}$.

Segundo a Lei n. ${ }^{\circ}$ 8.142/90 as diretrizes deste plano devem ser traçadas pelos conselheiros durante as Conferencias de Saúde (CS) e, após a sua elaboração pelo gestor e sua equipe, o mesmo deve ser apreciado, debatido e aprovado pelo CS, observando-se sua conformidade com o orçamento municipal ${ }^{4}$.

Dentre os conselheiros entrevistados, 74\% afirmaram terem ouvido falar sobre o PS de Viçosa. Entretanto, 52,1\% não sabiam informar se o PS do município havia sido apresentado aos conselheiros e $68,4 \%$ afirmaram que desconheciam o seu conteúdo (Tabela 2).

Tabela 2. Domínio de conhecimento sobre o Plano de Saúde (PS) e sobre o Relatório Anual de Gestão (RAG) pelos Conselheiros de Saúde do município de Viçosa, Minas Gerais, 2013.

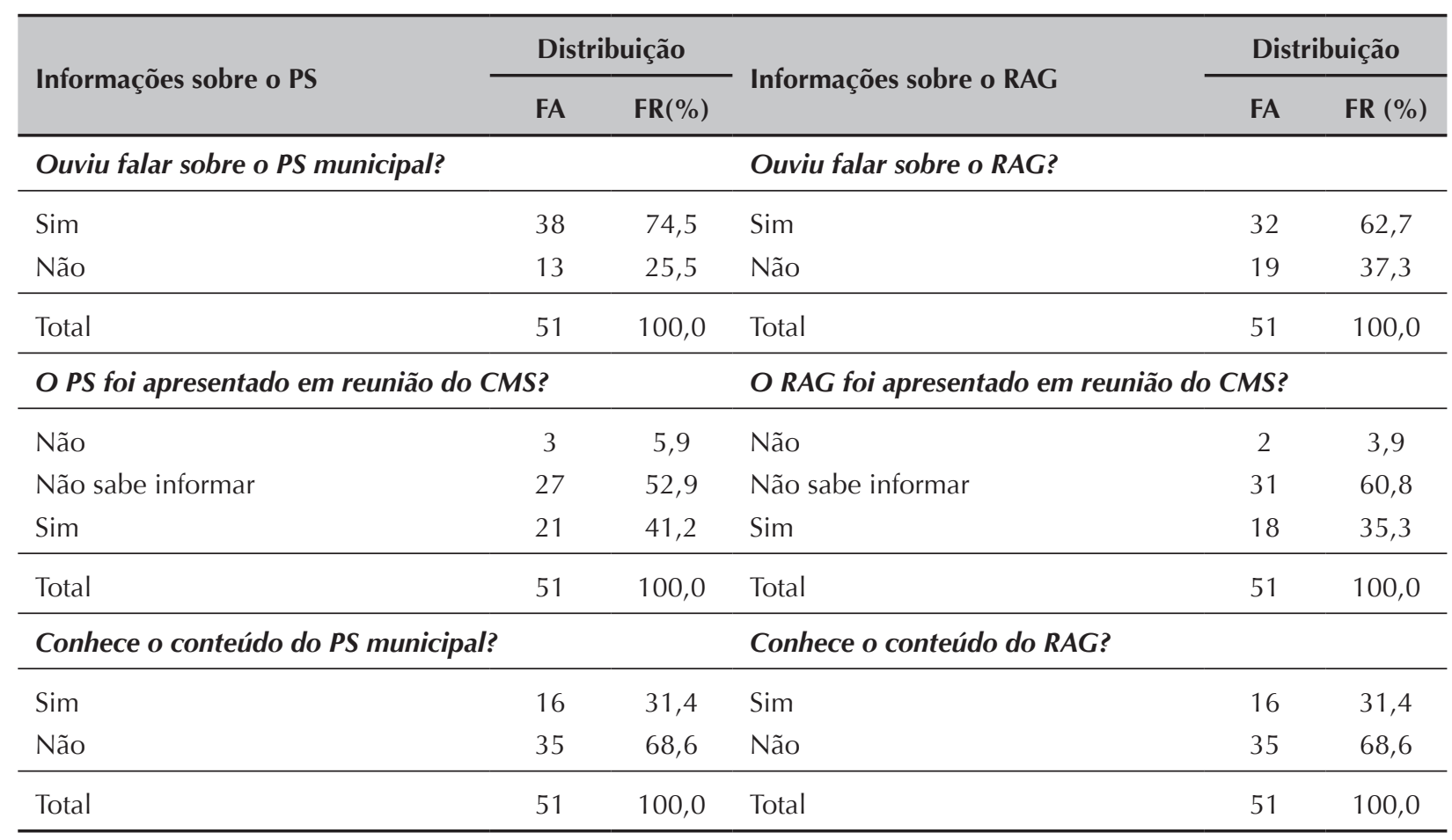

Fonte: próprios autores.

Segundo depoimento de conselheira, o PS de Viçosa vigente durante o período da pesquisa foi elaborado somente por ela, sem o estabelecimento prévio de suas diretrizes na Conferência Municipal de Saúde e, posteriormente não houve apreciação detalhada por parte do CMS/Viçosa.

A análise das atas das reuniões evidenciou que a elaboração e apreciação do PS não constaram como ponto de pauta de nenhuma reunião durante período estudado, fato este que contraria a expectativa de atuação do Conselho, como instância de caráter propositivo, formuladora de propostas relativas as políticas de saúde 2,10,20. $^{2}$.
De acordo com Carvalho ${ }^{5}$, a proposição é uma das maneiras de participação do cidadão no seu mundo. Segundo este autor, na área de saúde há uma série de questões a serem resolvidas e de problemas esperando por boas idéias e saídas. Destarte, todo processo de formulação de estratégias de saúde tem que passar pelo Conselho, pois é nele que a comunidade pode participar de forma propositiva, contribuindo e aprovando o PS ${ }^{1,10}$.

O fato de considerável número de conselheiros $(60,8 \%)$ desconhecerem o conteúdo do PS, além de representar descumprimento dos preceitos legais, representa perda da oportunidade de os mesmos atuarem de forma propositiva e, 
juntamente com o poder público, detectarem onde estão os problemas de saúde do município (diagnóstico); estabelecerem para onde se quer ir (objetivos), e como alcançá-los (estratégia) 5,7. Tal situação dificulta o estabelecimento de um pacto de cooperação e co-responsabilidades entre os agentes sociais envolvidos ${ }^{3}$.

Tal cenário remete a condição típica de De acordo com este autor, o sujeito encontra-se alienado quando destituído da possibilidade de exercício de sua capacidade crítica-reflexiva de analisar a sua realidade e a situação histórica que a constituiu, estando no mundo sem estar com ele e, conseqüentemente, sem o ímpeto criativo de transformá-lo ${ }^{21}$.

Tal condição de alienação somente pode ser superada por meio de uma prática educativa problematizadora e emancipadora, na qual os sujeitos encontrem condições propícias para o desenvolvimento do seu poder de captação e de compreensão do mundo que lhes aparece, em suas relações com ele, não mais como realidade estática, mas como realidade em processo, em constante transformação, e sobre a qual ele exerça o papel de sujeito ${ }^{21}$.

Por outro lado, a participação na construção do PS, a fiscalização dos resultados alcançados na sua execução é igualmente relevante, e também integra as atribuições legais conseIhistas. Estes resultados devem estar consolidados e apresentados no Relatório Anual de Gestão (RAG).

O RAG é um instrumento que tem por finalidade apresentar os resultados obtidos pela gestão em saúde no município durante o período de um ano, enfocando os aspectos essenciais contidos no PS referente a um determinado quadriênio, visando possibilitar o exercício do controle contínuo das políticas do SUS no município ${ }^{19}$.

O RAG apóia-se na determinação legal de oferecer transparência à sociedade sobre as ações e serviços de saúde, prestando contas dos recursos utilizados no período em análise. Constitui instrumento de controle previsto no previsto no art. $4^{\circ}$ da Lei $n^{\circ} 8.142 / 90$ e no art. 39 da Lei Complementar n. ${ }^{\circ} 141 / 12$, que condicionam a

transferência de recursos federais à apreciação e aprovação do RAG pelo $\mathrm{CS}^{15}$.

O RAG apresenta a síntese da movimentação dos recursos orçamentários e financeiros; análise sucinta das metas do PMS para o ano vigente, e relato analítico das ações desenvolvidas no exercício em questão ${ }^{19}$. Deve estar em conformidade com a Programação Anual de Saúde (PAS) e apresentar recomendações para o ano subsequente fundamentadas na avaliação crítica e propositiva das informações averiguadas.

No contexto de estudo, $62,7 \%$ dos conseIheiros afirmaram ter ouvido falar sobre o RAG, entretanto, $60,8 \%$ não sabiam informar se o mesmo havia sido apresentado ao Conselho e $68,6 \%$ disseram desconhecer o seu conteúdo (Tabela 2).

Contrariando este alto percentual de conselheiros que afirmaram não saber se o RAG foi apresentado e desconhecer o seu conteúdo, identificou-se dentre os pontos de pauta de reunião a apresentação de três Relatórios Anuais de Gestão, inclusive, enviados por email antes da reunião.

O primeiro relatório, referente ao ano de execução de 2007, foi apresentado em reunião ordinária do Conselho no dia 16 de abril de 2012, e foi aprovado pela maioria dos conseIheiros com uma única abstenção.

O motivo de pelo qual este RAG foi apresentado cinco anos depois do referido ano de execução não constava na ata, mas sua votação tardia por um Conselho cujo mandato não coincidiu com o ano de execução ao qual se refere o relatório indica, além de inadequação da gestão local em discutir as pautas em tempo hábil, o caráter eminentemente burocrático atribuído RAG pelo gestor, dificultando o exercício de seu papel instrumental no controle e monitoramento de ações e serviços de saúde.

Na concepção de Araújo ${ }^{22}$, trata-se de postura típica de uma administração pública que ignora a relevância prática destes instrumentos. Neste contexto, o prestador de contas parece não buscar sequer o atendimento dos itens obrigatórios, tornando o relatório como um dispositivo de mero cumprimento legal, cujo conteúdo 
não incorpora informações substantivas para controle social ${ }^{22}$.

Para fazer a diferença no exercício do controle social, a informação necessita ser tempestiva, isto é, deve ser divulgada rapidamente e de forma oportuna visando não perder a relevância para o processo decisório, bem como, para a avaliação das ações da Secretaria de Saúde, caso contrário, perde sua capacidade de influenciar a tomada de decisão, passando a não ter valor algum no momento em que é utilizada ${ }^{23}$.

O segundo RAG, referente ao ano de execução de 2011, também foi apresentado no dia 16 de abril de 2012, mas sua aprovação, por deliberação dos conselheiros, foi condicionada ao parecer de uma Comissão Especial constituída temporariamente com a finalidade exclusiva de analisar o RAG/2011. O parecer desta Comissão foi apresentado em reunião ordinária dezenove dias depois, e aprovado por unanimidade.

O terceiro último RAG apresentado no período de estudo, referente ao ano de execução de 2012, foi apresentado na reunião ordinária do dia 18 de fevereiro de 2013. Novamente, deliberou-se pela necessidade de apreciação prévia por uma Comissão Especial temporária, que apresentou seu parecer em reunião extraordinária no dia 26 de março de 2013 cujo quórum foi mínimo.

Ressalta-se que na etapa de observação participante, teve-se a oportunidade de acompanhar as reuniões das Comissões Especiais de apreciação dos RAGs e, em ambas, detectou-se grande dificuldade dos conselheiros em compreender o conteúdo técnico dos relatórios, inclusive, ao emitir parecer sobre o RAG/2011, o relator da comissão reconheceu a necessidade de capacitação dos conselheiros, conforme registrado na ata da reunião.

Destaca-se que somente $21,6 \%$ conselheiros entrevistados relataram ter participado de algum curso de Capacitação de Conselheiros de Saúde até o momento da entrevista.

Correia $^{10}$ em sua pesquisa junto a CMS de Alagoas, também observou a dificuldade de compreensão de termos técnicos e contábeis empregados nos instrumentos de fiscalização.
Explicações apresentadas por alguns conseIheiros a Gonçalves et al. ${ }^{23}$ quanto aos desafios do controle social incluíam o fato "das informações serem divulgadas e apresentadas nas reuniões plenárias em formato "muito técnico".

Observa-se um consenso entre os estudiosos no que diz respeito à compreensão de que os instrumentos de prestação de contas ainda são muito complexos e dificultam a avaliação, sendo primordial para o desempenho mais efetivo, que as informações sejam disponibilizadas de forma mais adequada e compreensível ${ }^{1,10,23}$.

Corroborando esta análise Gonçalves et al. ${ }^{23}$ observaram em sua pesquisa a dificuldade de relacionar o que fora estabelecido como meta e o que foi cumprido; a ausência de objetivos claros e a indefinição de prioridades como obstáculos presentes nos relatórios que impediam que os mesmos viessem a se configurar como ferramenta útil aos conselheiros. Tais condições pareceram plenamente evidenciadas nos RAGs apresentados ao CS/Viçosa.

Para Freire ${ }^{21}$, a ausência de preocupação de se fazer chegar a informação de forma condizente com a realidade de vida dos sujeitos constitui-se a razão pela qual muitos planos políticos ou pedagógicos fracassaram. Segundo este autor, foram muitos os exemplos de planos, de natureza política ou simplesmente docente, que falharam porque os seus realizadores partiram de sua visão pessoal da realidade, sem levar em consideração mínima os homens e a situação a quem se dirigia seu programa, a não ser como meras incidências de sua ação ${ }^{21}$.

Além dos obstáculos supracitados, também se observou a imprecisão de indicadores epidemiológicos obliterando o entendimento da realidade relativa à oferta e cobertura de serviços prestados.

Segundo Braathen ${ }^{24}$, uma nova informação para ser efetivamente apreendida necessita atender a três condicionalidades: primeiro, ser inteligível, isto é, passível de compreensão; segundo, ter plausibilidade, o que significa fazer sentido para quem a recebe e; terceiro, ser útil, mostrando-se um conhecimento importante de se saber e que apresenta alguma aplicabilidade. 
Outro desafio apontado por Correia ${ }^{10}$ diz respeito ao compromisso do gestor e sua equipe de disponibilizar de forma plena e transparente as informações.

Neste sentido, ressalta que mesmo em face da existência da determinação constitucional da prestação de contas do governo perante os conselhos, existem diversos artifícios contábeis que possibilitam mascarar a realidade.

Entretanto, a complexidade técnica ou possível mascaramento da informação contida nos RAG(s) sinalizam a razão pela qual um percentual menor de conselheiros (31,4\%) afirma conhecer o seu conteúdo, mas não esclarece o fato da maioria dos conselheiros $(60,8 \%)$ não terem sabido sequer informar se os mesmos foram apresentados em reunião do CMS/Viçosa, principalmente, se considerar-se que os RAG(s) foram encaminhados juntamente com as pautas das reuniões com antecedência.

Neste momento, impõe-se a reflexão acerca dos meios de comunicação disponíveis para levar a informação aos conselheiros, ou para que eles possam acessá-la quando considerarem necessário.

Destacou-se anteriormente que os RAG(s), assim como, demais documentos, geralmente, são disponibilizados aos conselheiros por correio eletrônico, ficando o acesso ao conteúdo destes documentos condicionado a disponibilidade de um computador com conexão à internet. Entretanto, no decorrer das entrevistas, foi possível constatar as condições de moradia e trabalho dos conselheiros que, em alguns casos, eram bastante precárias e ainda muito distantes da possibilidade de usufruir dos benefícios da chamada sociedade da informação, caracterizada por uma cultura digital centrada no uso intensivo das novas tecnologias de informação e comunicação ${ }^{25}$.

Contrariando a Quarta Diretriz da Resolução n. ${ }^{\circ}$ 453/12 do Conselho Nacional de Saúde (CNS) que determina que o Estado deve garantir dotação orçamentária, autonomia financeira, apoio técnico e necessária infraestrutura para pleno funcionamento do Conselho, o CMS/Viçosa também não dispunha de espaço físico com computador e internet que poderiam assegurar aos conselheiros o acesso a informação veiculada virtualmente.

Acrescente a estas limitações físicas o fato de alguns conselheiros não possuírem domínio de conhecimento e familiaridade com estas tecnologias de informação.

Essa situação de desigualdade de acesso e uso das tecnologias da informação entre conseIheiros de saúde também foi diagnosticada por Moraes et al. ${ }^{25}$. Estes autores concluiriam que a exclusão digital ocasiona assimetrias nos processos deliberativos dos colegiados em termos da capacidade crítica de análise e argumentação, principalmente, no contexto de um sistema em que a parcela significativa da informação em saúde é disponibilizada em sítios eletrônicos.

Outra hipótese explicativa para esta contradição entre os relatórios terem sido apresentados e discutidos, e ao mesmo tempo terem seu conteúdo desconhecido por parcela significativa dos conselheiros, reside na incipiente participação dos conselheiros nas reuniões: $11,8 \%$ dos conselheiros afirmaram não participar das reuniões do Conselho, 39,2\% afirmaram participar raramente e, menos da metade $(49,0 \%)$ disseram frequentar com regularidade.

Quando indagados sobre o motivo destas faltas, diversos fatores foram apontados, entre eles, destacou-se a ignorância dos temas abordados, o que leva a concluir pela possibilidade de ocorrência de um ciclo vicioso no qual a falta de conhecimento limita a atuação dos conseIheiros, levando-os a comportamentos de omissão e conformismo em detrimento à práticas de cidadania, participação e controle social $\left.\right|^{4,7,10,14}$.

\section{CONCLUSÃO}

Considerando que a participação e o controle social do SUS requerem o domínio de competências técnicas básicas, cujas ausências são contrárias às condições elementares da liberdade participativa, buscou-se neste estudo avaliar o domínio de informações sobre o SUS por parte dos conselheiros membros do CMS/Viçosa.

Foram eleitas como parâmetro de análise as LOS(s) (enquanto instrumentos jurídicos), o PS e o RAG (enquanto instrumento de 
técnico-administrativos), e observou-se desigualdade relativa ao conhecimento destes instrumentos por parte dos conselheiros. Os fatores determinantes desta desigualdade oscilaram entre o caráter burocrático atribuído aos mesmos; o formato extremamente técnico e codificado; a falta de apoio técnico; e as precárias infraestrutura e familiaridade para acessar informações veiculadas predominantemente virtualmente.

Somados a estes problemas relativos à compreensão e acesso à informação, percebeu-se a ocorrência de uma cultura política na qual prevalece ora a defesa de interesses particulares, ora o autoritarismo, ora a omissão ou desinteresse em relação às causas coletivas.

Ademais, considerando que a abertura a participação social na saúde ocorreu no contexto de um sistema de saúde cada vez mais complexo e em construção, no qual, continuamente, emergem novos instrumentos e procedimentos jurídicos e técnico-administrativos, conclui-se pela necessidade de capacitações permanentes dos conselheiros.

Ignorar a premência desta formação contínua possibilita aos detentores do poder político a perpetuação de práticas autoritárias e incompatíveis com as reais demandas em saúde da população.

A capacitação dos conselheiros nessa perspectiva é concebida como prática educativa promotora do libertação/emancipação na qual, além do repasse de informações essenciais sobre os conteúdos normativos que os conselheiros precisam dominar para o exercício pleno de suas atribuições, ocorra um processo de fomentação e consolidação de uma cultura de participação política democrática e de resistência ao autoritarismo e clientelismo típicos da cultura brasileira, especialmente nos municípios de pequeno e médio porte.

\section{REFERÊNCIAS}

1. Fracolli LA. Os Conselhos de Saúde e o fortalecimento da democracia brasileira. O Mundo da Saúde. 2005; 29(1):41-48.

2. Souza WS. Participação popular e controle social na saúde: democratizando os espaços sociais e agregando capital social. In: Matta GC, Pontes ALM. Políticas de saúde: organização e operacionalização do Sistema Único de Saúde. Rio de Janeiro: EPSJV/Fiocruz, 2007.p.115-138.

3. Gomes EGM. Conselhos gestores de políticas públicas: democracia, controle social e instituições. 2003. Dissertação (Mestrado em Administração) - Fundação Getúlio Vargas, São Paulo, 2003.

4. Brasil. Lei no. 8.142, de 28 de dezembro de 1990. Dispõe sobre a participação da comunidade na gestão do SUS e sobre as transferências intergovernamentais de recursos financeiros na área da saúde dá outras providências. Diário Oficial da União 1990; 31 dez.

5. Carvalho GCM. Participação da comunidade na saúde. Passo Fundo: IFIBE/ CEAP, 2007.

6. Bobbio N. O futuro da democracia: uma defesa das regras do jogo. 6.ed. Rio de Janeiro: Paz e Terra, 1986.

7. Cotta RMM, Campos AAO, Mendonça ET, Costa GD, Machado JC, Silva LS, Siqueira RL, Leão RT, Reis RS. Políticas de Saúde: desenhos, modelos e paradigmas. Viçosa: UFV, 2013.

8. Carvalho G. A saúde pública no Brasil. Estudos Avançados 2013; 27: 7-26.

9. Paim JS. Reforma sanitária brasileira: avanços limites e perspectiva. In: Matta GC, Lima, JCF. (Orgs.). Estado, sociedade e formação profissional em saúde: contradições e desafios em 20 anos de SUS. Rio de Janeiro: Fiocruz/EPSJV, 2008. p. 91-122. 10. Correia MVC. Desafios para o controle social: subsídios para a capacitação de conselheiros. Rio de Janeiro: Fiocruz, 2005. 11. Santos NR. Democracia e participação da sociedade em saúde. In: Matta, G.C.; Lima, J.C.F. Estado, sociedade e formação profissional em saúde: contradições e desafios em 20 anos de SUS. Rio de Janeiro: Fiocruz/EPSJV, 2008. p. $227-248$. 12. Minayo MCS, Assis SG, Souza ER. Avaliação por triangulação: abordagem de programas sociais. Rio de Janeiro: Fiocruz, 2005.

13. Bardin L. Análise do conteúdo. Lisboa: Edições, 2000.

14. Siqueira RL. Análise do perfil técnico, representativo e do potencial das estratégias inovadoras de ensino e aprendizagem no desenvolvimento de competências para a participação social no contexto do sistema único de saúde. Tese (Doutorado em Ciência da Nutrição) - Programa de Pós-Graduação em Ciência da Nutrição, Universidade Federal de Viçosa, Minas Gerais, 2014.

15. Brasil. Lei 8.080, de 19 de setembro de 1990. Lei Orgânica da Saúde. Dispõe sobre as Condições para a Promoção, Proteção e Recuperação da Saúde, a Organização e o Funcionamento dos Serviços Correspondentes e dá Outras Providências. Diário Oficial da República Federativa do Brasil, 1990; 19 set.

16. Matta GC. Princípios e diretrizes do Sistema Único de Saúde. In: Matta GC, Pontes ALM. Políticas de saúde: organização e operacionalização do Sistema Único de Saúde. Rio de Janeiro: EPSJV/Fiocruz, 2007. p.61-80. 
17. Braga IF. A sociedade civil e as políticas de saúde no Brasil dos anos 80 à primeira década do século XXI. In: Morosini MVGC, Reis JRF. Sociedade, estado e direito à saúde. Rio de Janeiro: EPSJV/Fiocruz, 2007.p.81-102.

18. Sen AK. Desenvolvimento como liberdade. São Paulo: Companhia das Letras, 2008.

19. Ministério da Saúde. Sistema de planejamento do SUS: uma construção coletiva. Brasília: Ministério da Saúde; 2009. (Série Cadernos de Planejamento, 2).

20. Siqueira JE. 25 anos do SUS: o que há para comemorar ?. O Mundo da Saúde. 2013: 37(1):56-64.

21. Freire P. Pedagogia do oprimido. 17.ed. Rio de Janeiro: Paz e Terra, 1987.

22. Araújo MAD. Responsabilização pelo controle de resultados no Sistema Único de Saúde. Revista Panamericana de Salud Pública 2010; 27: 230-236.

23. Gonçalves AO, Gonçalves RS, Tavares AL. O olhar dos Conselheiros de Saúde sobre os relatórios de prestação de contas no município de Natal (Rio Grande do Norte), Brasil. Saúde Soc. 2011; 20: 659-672.

24. Braathen PC. Professor: como ter sucesso no ensino superior. Viçosa: Aprenda Fácil, 2013.

25. Moraes IHS, Veiga L, Vasconcellos MM, Santos SRFR. Inclusão digital e conselheiros de saúde: uma política para a redução da desigualdade social no Brasil. Ciênc. Saúde Coletiva 2009; 14: 879-888. 